\title{
Vínculos complejos: cárceles, estado y sociedad en la provincia de Buenos Aires (Argentina) durante la segunda mitad del siglo XIX
}

\section{Complex relations: prisons, state and society in the province of Buenos Aires (Argentina) at the end of the 19th century}

\author{
Melina Yangilevich \\ (IGEHCS/IEHS/CONICET/UNCPBA)
}

Recibido: $15 / 03 / 2017$

Aceptado: 28/05/2017

Resumen: El texto reconstruye el funcionamiento de las cárceles ubicadas en la provincia de Buenos Aires (Argentina) durante la segunda mitad del siglo XIX, las dificultades planteadas por sus autoridades para su organización, las demandas elevadas por éstas y los propios detenidos al poder ejecutivo, así como los vínculos establecidos por quienes transitaron estos espacios al interior de estos establecimientos durante la primera década de funcionamiento. El análisis procura reconstruir de qué manera las cárceles de la provincia de Buenos Aires conformaron parte del pantano punitivo que definió la práctica del castigo y los modos en los que se vincularon estado y sociedad en la Argentina finisecular en un contexto de profundos cambios sociales, económicos y políticos.

Palabras claves: Cárcel - Estado - Provincia de Buenos Aires - Siglo XIX

\begin{abstract}
The text reconstructs the functioning of the prisons located in the province of Buenos Aires (Argentina) during the second half of the 19th century, the difficulties raised by its authorities for its organization, the demands raised by the authorities and the detainees themselves to the executive branch, as well as the Links established by those who transited these spaces into these establishments during the first decade of
\end{abstract}


operation. The analysis seeks to reconstruct the way in which the prisons of the province of Buenos Aires formed part of the punitive swamp that defined the practice of punishment and the ways in which state and society were linked in the Argentina finisecular in a context of deep social, economic changes.

Key words: Prison - State - Buenos Aires's Province $-19^{\text {th }}$ Century

\section{Introducción}

Hace varias décadas el historiador francés Marc Bloch sostuvo que la manera en la que los hombres eran juzgados era la mejor "piedra de toque" para comprender el sistema social en el que aquellos se encontraban insertos. ${ }^{1}$ Sin dudas, esta idea podría hacerse extensiva a las formas en las que las sociedades castigaban a las personas acusadas y condenadas de cometer un delito. En el mundo occidental la preocupación sobre cuáles son las formas y los modos adecuados de aplicación de las penas transitó un extenso recorrido con múltiples variaciones en tiempos y espacios. Hacia mediados del siglo XVIII la utilización de castigos ejemplificadores fue perdiendo validez en un contexto de disminución del poder y prestigio de las monarquías. ${ }^{2}$ En el espacio latinoamericano, la confianza en las posibilidades de rehabilitación que brindaría el sistema penitenciario fue común a las élites de diferentes países que comenzaron a abordar esta problemática, aunque los tiempos en los que se edificaron las instituciones penales fueron diversos. 3

La República Argentina no permaneció ajena a este contexto. Hacia fines del siglo XIX los debates en torno a la erección de cárceles y penitenciarías con características modernas constituyeron una parte indisociable del proceso de consolidación estatal y uno de los ámbitos desde el cual los grupos dirigentes esperaban mostrar la inserción del país en la modernidad. La provincia de Buenos Aires se presentaba como una de las partes más adelantadas del país en ese proceso. 4

\footnotetext{
${ }^{1}$ BLOCH, Marc, La sociedad feudal. Las clases y el gobierno de los hombres, Madrid, Akal, 1987 [1939], Libro II, p. 94.

${ }^{2}$ FARGE, Arlette, La vida frágil. Violencia, poderes y solidaridades en el París del siglo XVIII, México, Instituto de Investigaciones Dr. José María Luis Mora, 1994; FOUCAULT, Michel, Vigilar y castigar. El nacimiento de la prisión, Madrid, Siglo XXI, 1994 [1975].

3 SALVATORE, Ricardo y AGUIRRE, Carlos, The Birth of the Penitentiary in Latin America. Essays on Criminology, Prison Reform, and Social Control, 1830-1940, Austin, UTP, 1996.

4 La primera penitenciaría se construyó en la provincia de Mendoza, posiblemente influenciada por la inauguración de la erigida en la ciudad de Santiago de Chile. Ver GARCÍA BASALO, Alejo, “¿Fue un
} 
Fundamentalmente a partir de la organización de la justicia letrada en lo criminal iniciada en 1853 en el territorio ocupado por entonces. Para consolidar tales iniciativas, resultaba necesario contar con una legislación penal unificada y construir cárceles y penitenciarías que cumplieran con los requisitos considerados adecuados por entonces, así como sostener programas que permitieran que los condenados se reinsertaran en la sociedad. De tal manera, se esperaba completar el proceso de modernización vinculado al castigo.

Algunos de estos aspectos comenzaron a discutirse hacia la década de 1820, especialmente los vinculados a la formación de los magistrados encargados de juzgar a las personas 5 y a la organización de una estructura letrada capaz de sostenerse tanto en la ciudad como en la campaña. ${ }^{6}$ Esta última fue inviable por entonces y logró establecerse recién en 1853 a partir de los Departamentos Judiciales con cabeceras en San Nicolás, Mercedes y Dolores, que se sumaban al de la ciudad de Buenos Aires. ${ }^{7}$ La existencia de la justicia criminal implicaba necesariamente la de las cárceles donde los acusados esperaban la finalización de los procesos judiciales. Por ello, cárceles y tribunales criminales coexistieron en el mismo edificio o en casas aledañas. Las condenas cuando se hacían efectivas eran cumplidas, generalmente, en las filas de las fuerzas militares. ${ }^{8}$

La presente propuesta se propone reconstruir algunos aspectos del funcionamiento cotidiano de las cárceles, las dificultades planteadas por sus autoridades para su organización, las demandas elevadas por éstas y en algunos casos por los propios detenidos a las autoridades, así como los vínculos establecidos por quienes transitaron estos espacios al interior de estos establecimientos. El texto procura analizar de qué manera las cárceles de la provincia de Buenos Aires

panóptico la penitenciaría construida en Mendoza en 1865? Arquitectura y régimen en el primer reglamento penitenciario argentino", en XIV Jornadas Interescuelas/Departamentos de Historia, Mendoza, Universidad Nacional de Cuyo, 2013.

5 CANDIOTI, Magdalena, “Reformar útilmente la justicia': Jueces y leyes en la construcción del Estado en Buenos Aires en la década de 1820", en Marta IRUROZQUI y Mirian GALANTE (eds.), Sangre de Ley. Justicia y violencia en la institucionalización del Estado en América Latina, siglo XIX, Madrid, Ediciones Polifemo, 2011.

${ }^{6}$ FRADKIN, Raúl, “¿Misión imposible? La fugaz experiencia de los jueces letrados de Primera Instancia en la campaña de Buenos Aires (1822-1824)”, en Darío Barriera (comp.), Justicias y fronteras. Estudios sobre historia de la justicia en el Río de la Plata. Siglos XVI-XIX, Murcia, Editum, 2009.

7 YANGILEVICH, Melina, Estado y criminalidad en la frontera sur de Buenos Aires (1850-1880), Rosario, Prohistoria, 2012.

${ }^{8}$ YANGILEVICH, Melina, Estado y criminalidad, ob. cit., p. 155. 
conformaron parte del pantano punitivo que definió la práctica del castigo durante la segunda mitad del siglo XIX y principios del siglo XX. Tal análisis permitirá aportar al conocimiento sobre los modos en los que se conformaron, estrechamente vinculados, el Estado y la sociedad y donde las prácticas del castigo adquirieron un rol relevante en dicha definición en un contexto de profundos cambios sociales, económicos y políticos. Las fuentes utilizadas consisten en documentos tanto impresos como inéditos. Entre los primeros se encuentran diversas normativas. Entre los segundos contamos con correspondencia y un grupo de expedientes varios.

El texto se encuentra dividido en tres partes además de las reflexiones finales. En la primera describimos brevemente los estudios sobre la temática. En el segundo apartado se analizan las características de las cárceles existentes en el territorio bonaerense a partir de la creación de los departamentos judiciales a mediados del siglo XIX hasta la creación de los edificios carcelarios construidos específicamente para tal fin. En el tercer apartado, procuramos analizar las condiciones de funcionamiento de las cárceles, las problemáticas encontradas por los funcionarios e incluso los propios internos en relación al proceso de consolidación estatal.

\section{Las instituciones penitenciarias bajo la lupa}

Los estudios sobre el delito y el castigo en el espacio latinoamericano se incrementaron notablemente en los últimos tiempos, especialmente a partir del interés generado entre diversos especialistas de la historia social que ampliaron las indagaciones realizadas sobre estás temáticas hasta entonces sustentadas en los estudios jurídicos. ${ }^{9}$ De esta manera, los análisis pasaron a considerar, además de las instituciones y la legislación, a los sujetos que transitaban por esos espacios: presos, carceleros, policías y delincuentes. Así, las prisiones consideradas como instituciones representantes del poder estatal, arenas de conflicto, negociación y resistencia, espacios de socialización y cultura, entre otros aspectos constituyen una ventana desde la cual conocer la sociedad que construyó a esas instituciones. ${ }^{10}$

9 Sobre este punto puede consultar LEVAGGI, Abelardo, Las cárceles argentina de antaño (siglos XVIII y XIX), Buenos Aires, Ad Hoc, 2002 así como la bibliografía incluida en el texto.

10 AGUIRRE, Carlos, Dénle duro que no siente. Poder y trasngresión en el Perú republicano, Perú, AFINED, 2011 [2008], pp. 189 y ss. 
La historiografía argentina no estuvo ajena a este proceso. El interés en esta temática permitió que se ampliara tanto temporal como espacialmente los estudios centrados en los espacios de encierro así como los de la sociedad que los circundaba. ${ }^{11}$ En los últimos años se realizaron estudios sobre cárceles y penitenciarías ubicadas en diferentes espacios del territorio nacional como Tucumán ${ }^{12}$, Córdoba ${ }^{13}$, Mendoza ${ }^{14}$, Rosario $^{15}$ y Neuquén ${ }^{16}$, entre otros. Éstos mostraron las limitaciones de esos establecimientos y quienes los dirigían para concretar los objetivos propuestos por autoridades y expertos. A su vez, tales análisis señalaron semejanzas y diferencias con los establecimientos considerados modélicos por los contemporáneos: la Penitenciaría de Buenos Aires -luego Nacional- y la de Ushuaia. En esta multiplicación de estudios que contribuyeron, desde diferentes enfoques, a complejizar lo que Lila Caimari caracterizó acertadamente como un conjunto de “pantanos punitivos”. Este incluía a los establecimientos existentes así como a las prácticas que se desarrollaban en su interior. ${ }^{17}$ Sin embargo, en este complejo escenario los análisis realizados no alcanzaron a las cárceles que se erigieron en la provincia de Buenos Aires, paralelamente a la Penitenciaría porteña. Esta última se ponderó debido a las características de las celdas, los equipamientos, la disponibilidad de luz eléctrica entre otros aspectos- que la convirtieron en un arquetipo para mostrar tanto al interior del país -donde existían o se estaban programando instituciones similares- como al exterior para ilustrar la entrada del país en la modernidad punitiva, a pesar de los problemas que surgieron en diferentes etapas. ${ }^{18}$ De esta manera, la penitenciaria era expuesta junto con sus talleres y espacios de enseñanza donde los penados trabajaban

\footnotetext{
${ }^{11}$ En tal sentido resultó clave el estudio pionero de CAIMARI, Lila, Apenas un delincuente. Crimen, castigo y cultura en la Argentina, 1880-1945, Buenos Aires, Siglo XXI, 2004.

12 GONZALEZ ALVO, Luis, Modernizar el castigo. La construcción del régimen penitenciario de Tucumán (1880-1916), Rosario, Prohistoria, 2013.

13 LUCIANO, Melina, "La Penitenciaría de Córdoba: proceso de construcción, régimen interno y tensiones institucionales, 1887-1907", en Prohistoria, Año XVII, Nº 21, enero-junio 2014, pp. 131-155.

14 GARCÍA BASALO, Alejo, “¿Fue un panóptico la penitenciaría construida en Mendoza en 1865?”, ob. cit.

15 PIAZZI, Carolina, Justicia criminal y cárceles en Rosario (segunda mitad del siglo XIX), Rosario, Prohistoria, 2011.

16 BOHOSLAVSKY, Ernesto y CASULLO, Fernando, "Imágenes, prisioneros y política penitenciaria en la Patagonia en la primer mitad del siglo XX", en Annual Conference de la Society of Latin American Studies, Manchester, 2003.

${ }_{17}$ CAIMARI, Lila, Apenas un delincuente, ob. cit., pp. 109 y ss.

${ }^{18}$ CAIMARI, Lila, “Castigar civilizadamente. Rasgos de la modernización punitiva en la Argentina (18271930)”, en GAYOL, Sandra y KESSLER, Gabriel (comps.), Violencias, delitos y justicias en la Argentina, Buenos Aires, Editorial Manantial, 2002, p. 160.
} 
y aprendían así como se transformaron en objetos de estudio, a partir de la introducción de las indagaciones científicas en los establecimientos penales. Según Caimari convivieron allí la prisión-laboratorio y la prisión-fábrica en un proyecto común que implicaba la terapia laboral, la supresión de los tormentos y así como otras prácticas consideradas humillantes. ${ }^{19}$

Los más modestos edificios carcelarios construidos en paralelo al interior del territorio bonaerense buscaron mantener tales principios. Sin embargo, estuvieron lejos de alcanzar la relevancia de la cárcel porteña. En parte porque a diferencia de ésta que reemplazó al cabildo como espacio de encierro y produjo un corte -o lo intentó- en la aplicación del castigo penal, el resto de las cárceles provinciales tuvieron un derrotero menos espectacular y más atado a la administración de justicia criminal a la que incluso precedieron.

\section{Las cárceles como ‘escuelas de enseñanza para el vicio y el crimen’20}

La necesidad de contar con cárceles que fungieran como espacios de regeneración de los detenidos antes que como espacios de escarmiento fue expresada reiteradamente durante la primera mitad del siglo XIX. ${ }^{21} \mathrm{Y}$ por ello, no fue una novedad la inclusión de este principio en la Constitución Nacional de 1853 (artículo $18^{\circ}$ ), ni tampoco en la provincial sancionada un año después. ${ }^{22}$ Sin embargo, este principio estaba difundido con anterioridad en el Río de la Plata y como tal se reflejó en uno de los textos legislativos más relevantes sancionados por entonces: el Reglamento Provisorio de 1817. En el capítulo dedicado a la administración de justicia, el artículo $18^{\circ}$ afirmaba que "Siendo las cárceles para la seguridad y no para castigo de los reos, toda medida, que a pretexto de precaución sólo sirva para mortificarlos

\footnotetext{
19 CAIMARI, Lila, Apenas un delincuente, ob. cit., p. 107.

20 "Autorización al Poder Ejecutivo para invertir \$300.00o en la construcción de una penitenciaría", sesión del 28/7/1864, Diario de Sesiones de la Cámara de Senadores, Buenos Aires, Imprenta del Orden, 1865, pp. 68-69.

${ }^{21}$ LEVAGGI, Abelardo, ob. cit., pp. 54 y ss.

${ }^{22} \mathrm{El}$ artículo 167 afirmaba que "Las cárceles son hechas para seguridad y no para mortificación de los detenidos. Las penitenciarías serán reglamentadas de manera que constituyan centros de trabajo y moralización. Todo rigor innecesario hace responsables a las autoridades que lo ejerzan", Constitución de la Provincia de Buenos Aires, 1854, texto disponible en https://www.hcdiputadosba.gov.ar/includes/const_1854.html.
} 
maliciosamente, será corregida por los Tribunales Superiores, indemnizando a los agraviados por el orden de justicia." ${ }^{2} 3$

Siguiendo tales premisas, las autoridades de la recientemente creada provincia de Buenos Aires llamaron a una licitación para la presentación de propuestas de construcción de un panóptico. ${ }^{24} \mathrm{El}$ proyecto fue abandonado durante el gobierno de Manuel Dorrego debido a las dificultades económicas y la crisis posterior a la guerra con el Imperio de Brasil, finalizada en 1828. ${ }^{25}$ Las condiciones en la que se encontraba la cárcel pública del cabildo porteño eran deficientes. Con anterioridad, el juez letrado Bartolo Cueto había comunicado a Bernardino Rivadavia, por entonces secretario de gobierno, que la corrupción del aire y la falta de ventilación del edificio podían ocasionar alguna "peste". A ello sumó la opinión del alcaide para quien tal condición se veía agravada por la existencia de 38 indios pampa que "despedían desaseo, asquerosidad y fetidez", al punto que otros presos desistían de compartir los patios con ellos. ${ }^{26}$

Entre quienes reflexionaban sobre las características que debían reunir las cárceles durante la primera mitad del siglo XIX pareció haber acuerdo sobre la necesidad de separación entre condenados y encausados así como la distinción entre los grados de culpabilidad y sexos. Los diagnósticos sobre este punto eran pesimistas, debido a que en ocasiones los presos eran admitidos sin $\operatorname{sumarios}^{27} \mathrm{y}$ en otras las casas

\footnotetext{
23 "Reglamento Provisorio para la Dirección y Administración del Estado de 1817", sancionado por el Congreso Constituyente 1816-1819, en Documentos de la conformación institucional argentina, 17821972, Poder Ejecutivo Nacional, Buenos Aires, 1974.

24 Estas iniciativas formaron parte del proceso de modernización iniciado por Bernardino Rivadavia en 1821 como ministro de gobierno de la provincia. Entre las modificaciones más relevantes cabe mencionar la disolución de los cabildos y la separación de la administración de justicia (entre la justicia de paz lega y la letrada) de las funciones policiales. Rivadavia permaneció en Europa entre 1814 y 1820 donde entró en contacto con Jeremy Bentham, quien le sugirió considerar su idea del Panóptico. Sobre el tema véase GALLO, Ezequiel, Bernardino Rivadavia. El primer presidente argentino, Buenos Aires, Edhasa, 2012, pp. 43-56.

${ }^{25}$ GARCÍA BASALO, Alejo, “¿Un panóptico en Buenos Aires? La primera penitenciaria proyectada en Sudamérica”, en Épocas, $\mathrm{N}^{\circ}$ 8, 2013, pp. 47-90.

${ }^{26}$ Nota de Bartolo Cueto, juez de primera instancia, al ministro Rivadavia, Buenos Aires, 11/1/1823, Sala X 13-2-4, en Archivo General de la Nación, Argentina, (en adelante AGNA).

${ }_{27}$ Para un diagnóstico sobre la administración de justicia y la situación de los detenidos durante el periodo ver de BELLEMARE, Guret, Plan General de Organización Judicial para Buenos Aires, Facultad de Derecho y Ciencias Sociales, Universidad de Buenos Aires, 1949 [1829].
} 
particulares debían fungir como espacios de retención debido a la inexistencia de espacios adecuados, específicamente para las mujeres. ${ }^{28}$

En la provincia de Buenos Aires el devenir de las cárceles estuvo estrechamente ligado al de la justicia criminal dado que, al menos al interior del territorio, solían coexistir en los mismos espacios o muy próximos, al mismo tiempo que conformaban dos etapas diferentes pero vinculadas del castigo legal. ${ }^{29}$ Como analizamos en otro texto, la organización exclusiva de la administración de justicia criminal tuvo por propósito establecer el control estatal en el territorio bonaerense. ${ }^{30}$ Un espacio visualizado por algunos actores políticos como un desierto de civilización producto del extenso dominio ejercido por Juan Manuel de Rosas entre 1830 y 1852. ${ }^{11}$ Los lugares seleccionados para la instalación de los jueces letrados -San Nicolás, Mercedes y Dolores- no resultaron casuales ya que facilitaba instaurar una parte relevante de la presencia estatal en una porción importante del territorio provincial. Además en esos puntos existían o habían existido cárceles. ${ }^{2}$

El establecimiento de los juzgados hizo necesario contar con cárceles donde alojar a los procesados mientras se desarrollaban los procesos penales. Según los estudios mencionados, las condiciones de estos edificios fueron precarias dado que en ningún caso aquellos fueron diseñados para cumplir con las funciones de encierro. Las deficiencias fueron señaladas con frecuencia por los alcaides de las distintas cárceles. Según las autoridades, las construcciones existentes distaban de ser las adecuadas para retener a las personas alojadas. Por ello, en varios casos se las "aseguraba" con grilletes o se buscaban otras alternativas. Sin embargo, en ocasiones tampoco se contaba con los elementos necesarios a pesar de la asignación de un presupuesto por ley para el

\footnotetext{
${ }^{28}$ En 1830 el alcaide de la Cárcel Pública de San Nicolás daba cuenta que la "china” Eusebia Gaona acusada de dos robos- se encontraba "en calidad de presa en poder de Don Miguel Machuca, por no haber cómo asegurarla (...)". Véase CHERVO, Santiago y CAMARASA, Ester, "Cárceles de San Nicolás de los Arroyos del siglo XIX”, en IX Encuentro de Historia Regional del Sur Santafecino y Norte Bonaerense, Zárate, 2004.

29 PIAZZI, Carolina, ob. cit.

$3^{3}$ YANGILEVICH, Melina, Estado y criminalidad, ob. cit.

${ }^{31}$ Sobre este punto resulta claro el análisis realizado por Domingo F. Sarmiento en su clásico texto: Facundo. Civilización o barbarie.

$3^{2}$ FRADKIN, Raúl y RATTO, Silvia, “¿Qué hacer con los prisioneros españoles? La construcción del 'enemigo' y las formas de dejar de serlo, Buenos Aires, 1817-1819”, en Darío BARRIERA (coord.), La justicia y las formas de la autoridad. Organización política y justicias locales en territorios de frontera. El Río de la Plata, Córdoba, Cuyo y Tucumán, siglos XVIII y XIX, Rosario, Red Columnaria, ISHIR/CONICET, 2010, pp. 45-82; CERVO, Santiago y CAMARASA, Ester, "Cárceles de San Nicolás...", ob. cit.,
} 
servicio y custodia de las cárceles públicas de los departamentos judiciales. ${ }^{33}$ La escasez material pareció ser una constante. Por ello, no era inusual que se construyeran cepos para evitar las fugas y que se cobrara el "impuesto de carcelaje" a los presos para su manutención. 34

Hacia mediados de siglo tales condiciones parecieron mantenerse. En 1855 uno de los miembros de la Cámara de Justicia -Jorge Cernadas- respondió a una nota elevada por el juez letrado del Departamento del Norte al gobierno donde daba cuenta de una fuga y pedía grillos para evitar la huida de los detenidos. En su nota de respuesta el camarista le informaba que no contaba con tales elementos para enviar a San Nicolás al tiempo que la Cámara había dispuesto elevar una nota al gobierno solicitando la “urgente necesidad acerca de la construcción de la cárcel.” Pero además le advertía que las comunicaciones con el gobierno provincial debían realizarse a través del Superior Tribunal de Justicia provincial "para que éste tenga conocimiento (...) y pueda disponer lo conveniente para obtener una pronta y mejor resolución". 35 La nota citada ilustra otro aspecto del funcionamiento institucional, donde no existía un orden de preeminencias entre las autoridades que fuera respetado. De esa manera algunos agentes buscaron mantener y/o acrecentar márgenes de autonomía frente a sus superiores. En cierto sentido, estos vínculos complejos ilustran las dificultades de centralización por parte de las autoridades estatales de la provincia.

Posteriormente, a fines de 1868 el alcaide de la cárcel de Mercedes, Fructuoso Gómez, se dirigió al juez del crimen de ese departamento, José Antonio de Zabalía, con el propósito de informarle $-\mathrm{y}$ reclamar por su intermedio a las autoridades provinciales- la falta de pago de los estipendios correspondientes a los meses de septiembre, octubre y noviembre. Esta circunstancia, según el alcaide, implicaba que los guardiacárceles "además de servir de mal grado, esta(ba)n prestos a dejar el servicio.” La situación se veía agravada por la ausencia de uniformes y la escasez de

33 Ley $\mathrm{N}^{\circ}$ 25, "Servicio y custodia de las cárceles de los departamentos del Norte y del Sur", en KETZELMAN, Federico y DE SOUZA, Rodolfo, Colección completa de leyes del Estado y provincia de Buenos Aires desde 1854 a 1929, Buenos Aires, Lex, 1930.

34 CERVO, Santiago y CAMARASA, Ester, “Cárceles de San Nicolás...”, ob. cit., p.5.

35 RODRÍGUEZ MÉNDEZ, Lydia, Historia de la cárcel de Mercedes. Desde sus orígenes hasta 190o, Buenos Aires, s/d/e, 1989, pp. 37 y 38. 
armas, dado que para las 20 personas que custodiaban a los presos había solo 9 tercerolas y 6 machetes. Para cerrar su pedido agregó que

\begin{abstract}
"la escasez de gente actualmente y la razón que (...) encuentro a estos pobres hombres que no cuentan para sostener sus familias con más recursos que ese mesquino sueldo, me han impulsado a dirigir a V. S. la presente a fin de que V. S. se sirva arbitrar los medios que crea conveniente para evitar este mal, porque de lo contrario (...) todos están al parecer prontos a borrarse de la partida." 36
\end{abstract}

Los inconvenientes no terminaron allí, ya que una vez que el juez Zabalía elevó la nota del alcaide desde Contaduría de la provincia se le notificó que todos los sueldos adeudados fueron entregados al apoderado del juzgado de paz Don José Antonio Mónes Ruiz. Además se informó que las cuentas de la cárcel no habían sido rendidas desde el año anterior y que el responsable era el propio magistrado. Zabalía intimó al juez de paz para que informara cuántos eran los meses adeudados, el motivo de la falta de rendición de las cuentas, así como la persona responsable de realizarla. El juez de paz, Domigo Gorostiaga, respondió que los sueldos se habían abonado recientemente -a excepción del mes de octubre de 1868-, que la rendición era responsabilidad suya y que el vestuario había sido solicitado en reiteradas oportunidades. Así culmina el expediente, aparentemente con los sueldos abonados -en parte- y dejando pendientes cuestiones que no resultaban menores en la dinámica cotidiana de la cárcel. Los uniformes para los guardias -que permitiría una clara distinción entre estos y los detenidos así como las armas consideradas necesarias para el mantenimiento del orden.

Otro tema de preocupación era la persistencia de las fugas. En 1869 el alcaide de la cárcel de San Nicolás envió una nota al juez de Primera Instancia, Ventura Pondal para pedir su intervención ante las evasiones. Según su argumento, estas se veían facilitadas porque los "criminales (veían) la incapacidad de la guardia para contenerlos. (...) Los presos no ignora(ba)n el estado malísimo de la cárcel, que presenta(ba) toda

\footnotetext{
${ }^{36}$ Archivo Histórico de la Provincia de Buenos Aires 'Ricardo Levene', Ministerio de Gobierno, Argentina (en adelante AHPBA/MG), Juez del Crimen del Centro adjunta nota del alcaide de la cárcel pública, 1/1869/4/224/o/9/11/o75. Aun cuando no contamos con los elementes necesarios para comprobarlo, es probable que los argumentos y la amenaza velada que refiere la nota fuera transmitida por los propios guardiacárceles al alcaide.
} 
clase de inseguridades, (sabían) que las rejas esta(ba)n limadas; y que los techos no tienen ninguna seguridad".

Agregó que desde hacía dos años se encontraba pidiendo la reparación de la cárcel sin resultados positivos. ${ }^{37}$ Estos documentos, entre tantos otros de tono similar, muestran las dificultades en la administración cotidiana de las cárceles provinciales y de manera general, ilustra las propias dificultades del estado provincial para consolidarse. Por entonces, una parte importante de la administración de las cárceles descansaba en los jueces de paz. A todos los roles que estos funcionarios ${ }^{38}$ acumularon desde 1821, en las cabeceras departamentales se sumó la de fungir como responsables de las cuentas de las cárceles. Esto implicaba que una parte importante de la administración carcelaria descansaba sobre una institución -como la justicia de pazcuya condición estatal es discutible. 39 Autoridades que el gobierno provincial seleccionaba a partir de una terna enviada desde cada municipalidad y sobre la que tenía una capacidad limitada para influir, especialmente en aquellos espacios más alejados de la ciudad porteña..$^{\circ}$ En síntesis, la persistencia de los jueces de paz como articuladores de intermediaciones entre instituciones, autoridades y particulares, muestra las dificultades de los gobiernos provinciales para concluir la construcción de un estado con la autoridad suficiente para colocar bajo su égida un conjunto de

${ }_{37}$ La casa que hacía de cárcel estaba construida en barro, con paredes sencillas y que "no presta(ba) ninguna seguridad, ni garantía, para el objeto a que es destinada", en CERVO, Santiago y CAMARASA, Ester, "Cárceles de San Nicolás...", ob. cit., p. 9.

${ }^{38}$ Juan Carlos Garavaglia sostuvo que estos no eran funcionarios en el sentido estricto de la palabra dado que no cobraban sueldo, excepto cuando sumaban a ese cargo el de comisario. Véase GARAVAGLIA, Juan Carlos, "La justicia rural en Buenos Aires durante la primera mitad del siglo XIX (Estructuras, funciones y poderes locales)", en Poder, conflicto y relaciones sociales, el Río de la Plata (siglos XVIII-XIX), Rosario, Homo Sapiens, 1989, pp. 89-121.

39 Raúl Fradkin analizó la experiencia fallida de establecer la justicia letrada en la campaña durante la década de 1820 junto con la policía y la justicia de paz, sostiene que esta última -la menos estatal y más imbricada con el entramado social rural fue la que logró mayor arraigo y continuidad durante todo el siglo XIX. Véase del autor "¿Misión imposible? La fugaz experiencia de los jueces letrados de Primera Instancia en la campaña de Buenos Aires (1822-1824)", en Darío BARRIERA (comp.), Justicias y fronteras. Estudios sobre historia de la justicia en el Río de la Plata. Siglos XVI-XIX, Murcia, Editum, 2008, pp. 143-164.

${ }^{40}$ Esta temática requeriría de una reflexión más extensa que no es posible realizar aquí por razones de espacio. Para la primera mitad del siglo XIX véase YANGILEVICH, Melina, "Justicia de paz, territorio y construcción estatal en la frontera sur de Buenos Aires, primera mitad del siglo XIX", en XIV Jornadas Interescuelas/Departamentos de Historia, Universidad Nacional de Cuyo, Mendoza. Para la segunda mitad de siglo puede consultarse el minuciosos trabajo de DI GRESIA, Leandro, Instituciones, prácticas y culturas judiciales. Una historia de la Justicia de Paz en la Provincia de Buenos Aires: El Juzgado de Paz de Tres Arroyos (1865-1935), tesis doctoral, Universidad Nacional de La Plata, La Plata, 2014. 
prácticas, actividades y poderes que permanecían, aunque en retroceso, distribuidas en el entramado social.41

Como señalamos, en el ámbito provincial la necesidad de construir una penitenciaría estuvo presente desde las primeras décadas del siglo XIX. Sin embargo, adquirieron una dimensión más precisa a partir de la redacción del Código Penal por parte de Carlos Tejedor iniciada a mediados de la década de 1860 y aprobado para un conjunto de provincias, entre ellas, Buenos Aires en 1876. Previamente, la puesta en funcionamiento de los departamentos judiciales en el territorio provincial a partir de 1853 planteó el interrogante sobre las formas de retener y alojar a procesados y condenados. El diputado Seguí expresó con claridad en oportunidad del debate legislativo sobre la creación de los departamentos que el propósito de los mismos era hacer sentir la autoridad del Estado al interior de ese territorio. Por ello, la construcción de las cárceles aledañas a los departamentos judiciales pareció el siguiente paso en el proceso de civilizar el castigo. ${ }^{2}$

Debido a las demoras en la edificación, el problema del estado de las cárceles existentes no dejó de estar presente en diferentes ámbitos. En 1864, el entonces gobernador Mariano Saavedra propuso una ley para financiar la construcción de una penitenciaría en la ciudad de Buenos Aires. En la nota de fundamentación admitía que se trataba desde su origen de un "ensayo defectuoso" que no podía ajustarse por cuestiones del presupuesto provincial a las mayores exigencias existentes. Aun así, sostenía que la construcción de un edificio para tal fin resultaba necesario debido a que se encontraban "confundidos los procesados con los criminales de todos grados, condición, edad y aun sexo". A esto se sumaba "la humedad de los calabozos, la difícil circulación del aire, el hacinamiento y hasta desaseo de los presos, como consecuencia inherente á un estrecho e incómodo local. (...) Y pasando del "orden físico al moral" afirmó que las cárceles eran "forzosamente, por la vida común de los presos, escuelas

\footnotetext{
${ }^{41}$ Carlos Cansanello sostuvo que "fueron las autoridades públicas que construyeron el Estado las que se apropiaron de funciones que le eran necesarias, de herramientas de control social que buscaron y por cierto pudieron monopolizar. Y fue desde el Estado constituido que se licuaron progresivamente las potestades de los jefes de familia. Fue la absorción de todas esas capacidades lo que permitió el pasaje de la forma estatal moderna al Estado burgués, en que la intención moderna de abarcar todos los ámbitos políticos mutó en Leviatán.”, CANSANELLO, Carlos, “Justicias y penas en Buenos Aires. De los bandos de buen gobierno a la Constitución Nacional”, en Sandra GAYOL y Gabriel KESSLER (comps.), Violencias, delitos y justicia en la Argentina, cit., p. 126.

${ }^{42}$ CAIMARI, Lila, ob. cit., Apenas un delincuente, pp. 31 y ss.
} 
de enseñanza mutua para el vicio y el crimen."43 Los argumentos esgrimidos por Saavedra son similares a los del magistrado Bartolo Cueto cuando describía el estado de la cárcel en la década de 1820. Esto no puede llamar la atención, dado que se trataba del mismo edificio del antiguo Cabildo porteño. Características que, como se reflejan en diferentes textos, eran comunes al resto de las cárceles existentes en el territorio provincial.

\section{Las cárceles como 'verdaderas casas de corrección y de mejora' 44}

El año de 1869 puede considerarse como un momento de inflexión en torno a la temática penitenciaria.45 Un año antes Emilio Castro fue electo gobernador. En su opinión, la relevancia de erigir cárceles era mayor a la del tendido de los ferrocarriles, por entonces, símbolo indiscutible del progreso social y económico. Por ello, fue uno de los principales impulsores de tal iniciativa. ${ }^{46}$ Ese mismo año Castro convocó a un concurso de presentación de planos y presupuestos para la construcción de una cárcel celular que luego podría transformarse en una penitenciaría para la ciudad de Buenos Aires. La necesidad de contar con estos establecimientos pareció responder a necesidades de diferente tipo, largamente reiteradas. Entre los argumentos se señaló la obligación de cumplir con el precepto constitucional que hacía referencia a que las cárceles debían ser para seguridad y no mortificación de los penados. 47 El proceso fue dificultoso -según el jurado, los proyectos no cumplían con las condiciones

\footnotetext{
43 Ídem nota 1. El resaltado es nuestro.

44 Mensaje del Poder Ejecutivo a la Honorable Asamblea General Legislativa del $1^{\circ}$ de Mayo de 1872 , en Registro Oficial de Buenos Aires (en adelante ROBA), Imprenta del Mercurio, 1873, p. 231.

45 Por otro lado, la periodización señalada se ve reforzada por la temporalidad de las fuentes documentales con que contamos. En el Archivo General de la Nación de la Argentina el periodo comprendido por la documentación agrupada en el fondo "Cárceles y Presidio" va de 1821 a 1869. Mientras que en el Archivo Histórico de la Provincia de Buenos Aires "Ricardo Levene" ubicado en la ciudad de La Plata, el fondo del Ministerio de Gobierno donde se incluye la parte relativa a las cárceles y la penitenciaría se inicia en 1867.

${ }^{46}$ GARCÍA BASALO, Carlos, Historia de la Penitenciaría de Buenos Aires, (1869-188o), Buenos Aires, Editorial Penitenciaria Argentina, 1979, reproducido en LEVAGGI, Abelardo, Las cárceles argentinas, ob. cit., p. 67.

$47 \mathrm{El}$ decreto de convocatoria del concurso para la presentación de planos y presupuestos para la construcción de una cárcel en la ciudad daba cuenta de la "urgencia" de cumplir con lo establecido en la Constitución. Decreto relativo a la construcción de un edificio para Cárcel de la Capital, 10/7/1869, en $R O B A, 1870$, p. 331.
} 
establecidas y el terreno elegido no era apto para la construcción- aunque finalmente se optó por la propuesta presentada por Ernesto Bunge. $4^{8}$

Por otro lado, ese mismo año y en un intento por ordenar el funcionamiento de las cárceles provinciales, el Superior Tribunal de Justicia aprobó un reglamento para la cárcel porteña. 49 Este incorporaba algunos de los preceptos del sistema penitenciario como la separación de acuerdo a la gravedad del delito, aumentaba el plantel fijo incorporando un segundo alcaide, un médico, un capellán, un ordenanza y once llaveros. Su análisis -que requeriría de mayor espacio del que podemos realizar aquíresulta necesario para comprender el funcionamiento de este tipo de instituciones. ${ }^{50}$ No solo para dar cuenta de las expectativas implícitas de quienes elaboraron tales reglamentaciones, sino también porque revelan un conjunto de prácticas que se pretendían limitar y se contradecían con los principios penales que comenzaban a ganar espacio. $5^{1}$

El interés por la modernización de estas instituciones no se limitó a la ciudad de Buenos Aires, sino que se hizo extensivo a las cárceles de los departamentos judiciales del territorio provincial. En 1872 y 1873 se autorizó al gobierno destinar más de un millón de pesos para la construcción de edificios para cárcel y casa de justicia en San

\footnotetext{
${ }^{48}$ Ley ordenando la construcción de una nueva Cárcel y se provee de los recursos necesarios, 30/7/1872, en $R O B A, 1873$, pp. 315-317. Bunge fue uno de los arquitectos más importantes de su tiempo. Además de estos establecimientos diseñó la Penitenciaría de Buenos Aires, la iglesia de Santa Felicitas y diversas residencias de las familias más acaudaladas. Su hermano Octavio que fue abogado, ingresó en el poder judicial en 1869, en 1873 fue designado juez letrado en lo pena, luego miembro de Cámara de Apelaciones en lo criminal, correccional y comercial y en 1892 ministro de la Suprema Corte. Véase GARCÍA HAYNES, Mateo, "La familia Bunge: modernos y segundones en las clases altas porteñas del '900", en Terceras Jornadas Nacionales de Historia Social, La Falda, 2011.

49 SERVICIO PENITIENCIARIO BONAERENSE, Historia Institucional, tomo I, La Plata, Ministerio de Justicia, 2006, pp. 333-338.

50 GONZÁLEZ ALVO, Luis, Modernizar el castigo. La construcción del régimen penitenciario en Tucumán, 1880-1916, Prohistoria, Rosario, 2013.

${ }^{51}$ El reglamento expresaba que los empleados de las cárceles debían exigir a los presos "la más completa obediencia y de considerarlos como individuos sometidos a su autoridad, y no como a compañeros" (art.2, título I). Asimismo resulta ilustrativa la lista de las prohibiciones establecidos para los alcaides: primero: "comprar ó vender á los presos, cualquier objeto ó celebrar con ellos contrato alguno, mientras permanezcan en prisión. Segundo: usar de sus servicios para sí, ó sus subalternos. Tercero: Permitir que se introduzcan bebidas espirituosas de ninguna clase, sin mandato espreso del médico; y en más cantidad que la que éste determinare; ó la de armas u otros objetos perniciosos. Cuarto: Hacer comer á los detenidos en su mesa, y en general, permitir que éstos, ó sus subalternos, falten con pretesto alguno á la observancia del presente reglamento.” (art. 6, título II), Ver Servicio Penitenciario Bonaerense, Historia Institucional, ob. cit., pp. 333-334.
} 
Nicolás ${ }^{52}$ y Dolores53, respectivamente. Al igual que la Penitenciaría de Buenos Aires, aquellas fueron encargadas a Bunge. En el caso de Mercedes, en 1867 se autorizó a la municipalidad para construir edificios públicos, entre los que se encontraba el cabildo. La erección de la cárcel en este punto, encargada al arquitecto Pedro Benoit, fue aprobada en 1877 , aunque existen registros de pago para dicha obra durante el año anterior. 54

Como se mencionó, desde la asunción de Castro se impulsó fuertemente el avance en la erección de estos establecimientos. En el mensaje dirigido a la Asamblea Legislativa, Castro sostuvo que "nuestras cárceles no alcanza(ba)n a contener el número de presos que existe en ella, ni aun conservándolos como se mantienen en contravención a las más sencillas reglas de higiene." La construcción de edificios específicos no tenía como propósito solo la "seguridad de los presos", sino que aquellos fungirían como "verdadera(s) casa(s) de corrección y de mejora para los criminales empleando en ellas el sistema penitenciario." 55

La vigencia de estas nociones se plasmó en la reforma constitucional provincial aprobada en 1873. En el artículo 27 se retomaba el principio de que las cárceles eran "hechas para seguridad y no para mortificación de los detenidos." Y se agregaba que las penitenciarías serían reglamentadas de manera que se constituyeran en "centros de trabajo y moralización" y que la aplicación del rigor "innecesario" haría responsables a las autoridades que lo ejercieran. Por otro lado, el artículo 202 reforzaba el control de la municipalidad -a cargo de los jueces de paz- de una parte no menor de las funciones policiales -entendidas en sentido amplio- y de las cárceles..$^{6}$

\footnotetext{
$5^{2}$ Decreto, 10/17/1872, en ROBA, Año 1872, pp. 387-388.

53 Autorización al Ejecutivo para invertir hasta 1 millón quinientos mil pesos, en un edificio para Cárcel y Casa de Justicia en Dolores, 3/9/1873 y Comisión para estudiar é informar sobre los planos para Casa de Justicia y Cárcel de Dolores, 27/10/1873, en ROBA, Año 1873, pp. 444 y 590.

54 Ley 694, "Se autoriza el pago del déficit en la construcción del Cabildo de Mercedes. (Rodríguez Méndez, 1989: 58) No queda claro el porqué del uso del término cabildo, es posible que fuera utilizada aludiendo a la municipalidad. Ambas instituciones estaban ligadas a la noción de gobierno local aunque en contextos muy diferentes. En el Río de la Plata los cabildos desaparecieron entre las décadas de 1820 y 1830. Las municipalidades previstas en la constitución nacional de 1853 se organizaron con posterioridad en las que e gobierno local estuvo en manos de jueces legos que adquirieron diferentes denominaciones de acuerdo a las provincias.

55 Ídem nota 17.

${ }^{56}$ Constitución de la Provincia de Buenos Aires (1873-1889), El inciso 4 del artículo 202 establecía que entre las atribuciones del régimen municipal se encontraban "Tener a su cargo la policía de seguridad, ornato y salubridad, los establecimientos de beneficencia, los asilos de inmigrantes que sostenga el
} 
Por su parte, las máximas autoridades judiciales no fueron ajenas a estas preocupaciones. En 1876 la Suprema Corte provincial sostuvo que debido a las características de las cárceles, las penas aplicadas no cumplían con el fin del mejoramiento del penado por medio de la educación y tampoco era ejemplo para la sociedad por medio del conocimiento público que "dejando penetrar la persuasión de la impunidad, eleva el número de delitos”. La penitenciaría despertaba una cuota de esperanza, nada novedosa. Esos problemas terminarían con "el edificio de la más notable penitenciaría de la América Latina, en donde la corrección moral y el conocimiento del mal impuesto, hará extraordinaria disminución en el hoy alto número de penados". 57

El optimismo frente a los futuros beneficios que las cárceles y penitenciarías brindarían contrastaba con el diagnóstico sobre los establecimientos existentes. A las condiciones edilicias y de higiene mencionadas, se agregaban las dificultades en la administración, considerada siempre como problemática. Por una parte, la entrada y salida de procesados y condenados estuvo regida por los jueces letrados a cargo de los departamentos judiciales y a partir de 1875, de las Cámaras de Apelaciones instaladas ese año. Mientras que el mantenimiento del orden al interior y el funcionamiento cotidiano estuvo a cargo de los alcaides y luego de los directores, aunque en ocasiones las Cámaras de Apelaciones de los departamentos asumieron ese control. 58

Los relatos sobre la construcción de las cárceles y casas de justicia para los tribunales letrados dan cuenta de las dificultades del proceso que se tradujo en la demora de la conclusión de las edificaciones. Las cárceles se inauguraron en paralelo con la penitenciaría de Buenos Aires en 1877. Sin embargo, el conjunto de las obras no estaban terminadas. Dos años después, por ley se autorizó la construcción de los muros de circunvalación de las cárceles de Dolores y San Nicolás. Pasarían otros dos años para que una nueva ley acordara el monto necesario para llevar a cabo dicha construcción. La falta de estas medidas de seguridad prolongó la utilización de otras, como los grillos

Estado, las cárceles y la viabilidad.”, disponible en http://www.hcdiputadosba.gov.ar/includes/const_1873.html.

57 CORVA, María Angélica, Constituir el gobierno, afianzar la justicia. El Poder Judicial de la provincia de Buenos Aires (1853-1881), Rosario, Prohistoria, 2014, p. 266.

${ }_{58}^{8}$ Un incidente entre el alcaide de cárcel de Mercedes y el oficial de guardia propició que el piquete quedara bajo el mando de la Cámara de Apelaciones. Véase RODRÍGUEZ MÉNDEZ, Lydia, ob. cit., p. 98. 
que eran claramente contradictorias con los textos constitucionales. El empleo de estos instrumentos fue prohibido recién en 1890. Este no fue el caso de la cárcel de Mercedes, que contó con un muro de circunvalación construido en conjunto con el edificio central. Por ello, allí se requería un número menor de guardiacárceles que en las restantes.

\section{Mapa $\mathrm{N}^{\circ}$ 1: Ubicación de las cárceles y penitenciaría provinciales (1877-1882)}

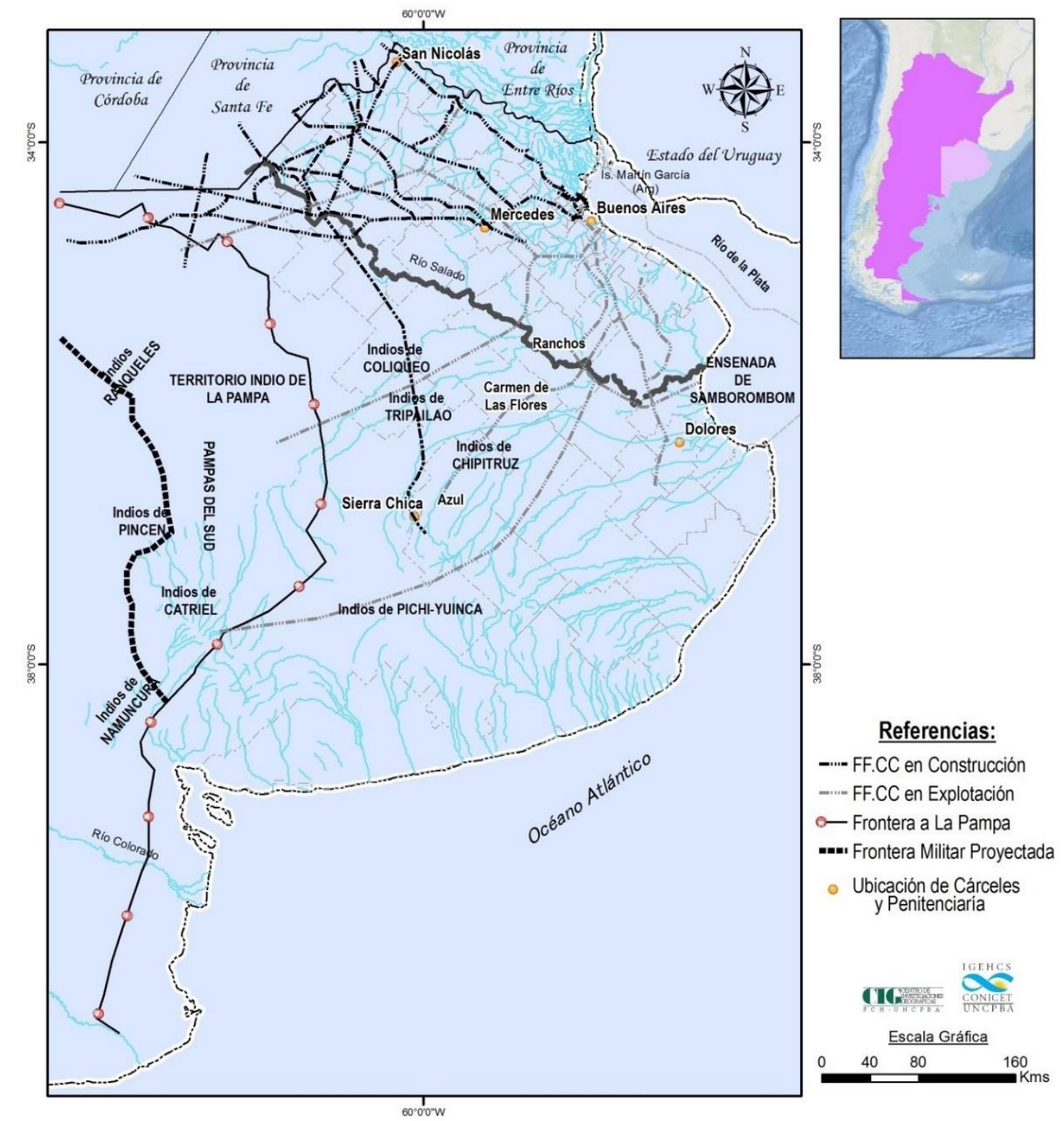

Fuente: elaboración propia de la Lic. Lorena La Macchia a partir del Mapa de la provincia de Buenos Aires con designación de partidos, de F. Taylor (1877), disponible en http://trapalanda.bn.gov.ar/jspui/handle/123456789/5123. 
La inauguración de las cárceles dio lugar a la asistencia de las más altas autoridades políticas y eclesiásticas. En la de Mercedes asistieron el entonces presidente Nicolás Avellaneda, el Gobernador Carlos Casares y el obispo Aneiros, entre otros. Las palabras de Avellaneda ratificaron la convicción en la capacidad de las cárceles civilizadas no solo para transformar a los hombres que entraban a ellas, sino también a los pueblos donde eran construidas. La construcción de la nueva cárcel fue considerada por el presidente como un "gran hecho" dado que el poblado hasta no demasiado tiempo atrás era conocido como "la Guardia de Mercedes (...) un fortín avanzado en presencia del desierto y sobre la línea extrema de la frontera civilizada.” 59 Esta idea, propia del grupo dirigente de la época, se trasluce también en el mapa incluido que incluye la línea de frontera y la ubicación de los diferentes grupos indígenas en el territorio de la campaña.

No obstante, el adelanto que representaba la inauguración de los nuevos edificios para las cárceles y juzgados, la administración económica de aquellas continuó dependiendo de las municipalidades y de los jueces de paz. En la misma nota donde el juez lego de Mercedes, Waldo Romero, se notificaba del traspaso de mando de la guardia de la cárcel a la Cámara, solicitó lo mismo para la responsabilidad administrativa. Sostuvo que "ya demasiado tiene este Juzgado de Paz, de tal modo que podrá cumplir más eficazmente las demás obligaciones." ${ }^{60}$ Sin embargo, los jueces de paz de Dolores, Mercedes y San Nicolás continuaron elevando al Ministerio de Gobierno las cuentas de las cárceles por lo que, pese a los pedidos, continuaron con la responsabilidad administrativa de estos establecimientos. ${ }^{61}$

Como se mencionó, un aspecto central en la administración de las cárceles era la seguridad que descansaba en la actividad de los guardiacárceles. Cuando se organizaron los departamentos judiciales, las cárceles donde se alojaban los procesados eran vigiladas por otros hombres, destinados por los jueces de paz a servir como vigilantes por considerárselos "vagos y desobedientes". En 1855 el jefe de un

59 RODRÍGUEZ MÉNDEZ, Lydia, ob. cit., p. 89.

6o AHPBA/MG, Nota del juez de paz Waldo Romero al Ministerio de Gobierno, 1/1877/3/258/o/7/93/075.

${ }^{61}$ AHPBA/MG, San Nicolás de los Arroyos adjunta las cuentas de los suministros hechos a la cárcel en el mes de enero pasado, 1/1880/3/143/o/106 y AHPBA/MG, Cuentas de la cárcel de Dolores, $1 / 1880 / 4 / 202 / 0 / 032$. 
regimiento se dirigió a Irineo Portela, Ministro de Guerra y Marina, para pedirle que le permitiera

\begin{abstract}
"levantar un piquete veterano de los vagos, y desobedientes al enrolamiento que abundan en estos partidos, para con estos mismos dar guardia a la cárcel de este pueblo, y de este modo aliviar la fuerza de Guardia Nacional que diariamente tiene que dar guarda a dicha cárcel, con la presencia de las partidas celadoras y haber pedido (...) auxilio de fuerzas al Sr. Juez del crimen de los Departamentos del Sur Dn Felipe J. Coronel.

Se ha permitido el infrascripto distraer la atención del ministro sobre este punto por ser enteramente imposible seguir dando este servicio en razón de estar la mayor parte de esta Guardia Nacional en sus trabajos de guerras, y cosechas de trigo a que se ha dedicado con esmero."62
\end{abstract}

La respuesta del gobierno fue que proveería oportunamente. Las palabras del comandante son claras. Pide liberar del servicio prestado en la cárcel de Dolores a los miembros de la Guardia Nacional que resultaban necesarios en los espacios de frontera para contener a los grupos indígenas. Propone reemplazarlos por otros hombres que se reclutaban a partir del castigo aplicado por considerárselos vagos. Sin embargo, no solo estos eran destinados, sino que algunos miembros de la Guardia Nacional habían sido enviados a cumplir la pena del servicio de las armas por diferentes faltas y delitos. Es decir que la seguridad de las cárceles descansaba sobre personas condenadas. No fue hasta 1881 cuando se procuró profesionalizar esta actividad. Ese año se organizó un servicio específico de guardiacárceles a partir de una parte de las fuerzas militares existentes en la provincia. Se establecieron cuatro compañías integrada cada una por 1 capitán, 1 teniente, 1 subteniente, 1 sargento $1^{\circ}$ y otro $2^{\circ}, 1$ cabo $1^{\circ}$ y otro $2^{\circ}$ y 34 guardianes lo que quedaban bajo la dependencia del Jefe de Policía. Ello implicó reunir dos batallones preexistentes -el de Guardiacárceles y el $2^{\circ}$ Batallón Provincial- y prescindir de oficiales y soldados que fueron dados de baja para ajustarse al presupuesto existente.63 Esta pareció ser la razón central para establecer esta organización, a pesar de las diversas demandas sobre la falta de hombres para la vigilancia de los presos. Los guardiacárceles quedaron bajo la dependencia del jefe de policía de la provincia.64 En consonancia con lo estudiado por Sandra Gayol para la ciudad de Buenos Aires, los guardicárceles que sirvieron en los establecimientos

\footnotetext{
62 AGNA, Sala X, 19-3-3.

63 RODRÍGUEZ, Adolfo y ZAPPIETRO, Eugenio, Historia de la Policía Federal Argentina a las puertas del tercer milenio, Buenos Aires, Editorial Policial 1999, pp. 143-147 y 155.

64 LEVAGGI, Abelardo, ob. cit., p. 178.
} 
provinciales carecían de formación específica y en ocasiones no sabían leer y escribir. Tales condiciones no eran exclusivas de los escalones más bajos, ya que podían incluir a los oficiales. El propio Inspector de Cárceles, Ramón Falcón, en una nota al ministro de gobierno Nicolás Achával sostuvo hacia 1883 que "no siempre se puede contar con oficiales que supiesen perfectamente sus obligaciones."65

Esta organización de los guardiacárceles centralizada bajo el mando del jefe de policía fue breve. Una sucesión de diferentes conflictos terminaron por convencer a las autoridades provinciales que la guarnición existente en Sierra Chica quedara bajo las órdenes del director de la cárcel, Pascual Uriarte. En 1883 en el expediente mencionado anteriormente se discutió el servicio que debían prestar los guardiacárceles en la Penitenciaría de Sierra Chica. ${ }^{66}$ Falcón afirmó que el director del establecimiento, Pascual Uriarte se inmiscuía en asuntos que no eran de su incumbencia dando lugar a situaciones anómalas. Asimismo, relató que 2 oficiales enviados allí se presentaron casi inmediatamente en la Inspección para presentar su renuncia y lo atribuyó al accionar del director. En respuesta, Uriarte sostuvo que en Sierra Chica, a diferencia de Mercedes, Dolores y San Nicolás, no había "teatros, cafés, etc. donde la oficialidad (...) ha llegado a lanzarse (...) armados con 14 remington para pelear a la Policía local”. Por el contrario, sostuvo, "Sierra Chica [era] un destierro. Se guardan los criminales más famosos y por toda seguridad la vigilancia, el desvelo y un servicio bajo la base de una moral y disciplina a toda prueba." En su opinión, estas eran las razones por la que los oficiales y soldados preferían otros destinos más apacibles. Por ello propuso que el cuerpo de guardiacárceles de la penitenciaría quedara bajo su mando, excluyéndolos del mando del jefe de policía. Sugerencia con la que Falcón estuvo de acuerdo. Finalmente, el ministro de gobierno Achával accedió al pedido no solo por la distancia que separaba a ese punto de la capital sino porque, según sostuvo, era el único medio de saldar todas las dificultades que se presentaban en el servicio de los oficiales.

\footnotetext{
65 AHPBA/MG, Buenos Aires, De la Inspección de Cárceles al Ministro de Gobierno Nicolás Achával, 16/7/1884, 1/1884/13/1187/16/11/083.

${ }^{66}$ Esta se construyó en esa localidad luego de la federalización de la ciudad de Buenos Aires y por tanto, del paso de la penitenciaría porteña a manos del gobierno central. Según la descripción realizada en diversos expedientes, a diferencia de las cárceles provinciales, esta institución contaba con un galpón para alojar a los penados y las medidas de seguridad consistían en dos zanjas que procuraban evitar la posible evasión, para lo que resultaron inútiles. AHPBA/MG, Sobre evasión de presidiarios, 118837 618-0 083-500.
} 
Las condiciones en que se desenvolvía las actividades en Sierra Chica -el aislamiento referido, la autoridad ejercida por Uriarte junta con la del juez de paz- se combinaron para generar conflictos que excedieron las paredes de la cárcel. Este fue el caso sucedido en el partido de Olavarría, donde se encontraba la mencionada penitenciaría. En 1885 el juez de paz, José Almada, elevó al ministerio de gobierno un sumario por lo que llamó un "abuso de autoridad y usurpación de funciones" realizado por un grupo de guardiacárceles por orden del director de la penitenciaría, Pascual Uriarte. ${ }^{67}$ Según la denuncia un grupo de hombres allanó varios domicilios y detuvo de manera violenta a un grupo de vecinos, a quienes obligaron además a vestir con uniformes. Según la nota de descargo de Uriarte, uno de los detenidos era desertor aunque no da cuenta de los motivos que lo llevaron a detener al resto de las personas. En la opinión del juez de paz, el director se excedió en sus funciones que no podían traspasar los límites de la penitenciaría. Almada pidió al ministro Nicolás Achával que resolviera a la brevedad el incidente, ordenando a Uriarte no repetir tales actos de violencia y pidió la libertad de los detenidos. Sin embargo, pocos días después envió otra misiva en un tono sustancialmente diferente donde afirmaba que el conflicto se había resuelto "amistosamente" y que quienes estaban detenidos habían sido liberados. Aunque el asesor del gobierno sostuvo la necesidad de formar una comisión para esclarecer los hechos el expediente se cierra sin una resolución, por lo que es posible suponer que allí culminó el sumario y que la disputa se resolvió de manera informal. Tales prácticas de negociación estaban extendidas en la campaña bonaerense, donde los juzgados de paz eran los espacios específicos donde se resolvían los conflictos locales de diferente tipo. ${ }^{68}$ De tal modo, no era inusual que se iniciara una denuncia con el propósito de forzar una negociación entre las partes en disputa, como parece indicar se trató este caso. Varios de los problemas referidos a la infraestructura, escasez de presupuestos, baja formación de los guardiacárceles, entre otros muchos aspectos, continuaron hasta entrado el siglo XX.69

\footnotetext{
${ }^{67}$ AHPBA/MG, Olavarría, Juez de paz eleva un sumario levantado por abusos del "Guardia de Cárcel", 1/1885/8/533/0/17/10/083.

68 PALACIO, Juan Manuel, La paz del trigo. Cultura legal y sociedad local en el desarrollo agropecuario pampeano 1890-1945, Buenos Aires, Edhasa, 2004, p. 214.

69 SILVA, Jeremías, "El sistema penitenciario del Estado nacional entre 1930 y 1943", en Ricardo Salvatore y Osvaldo Barreneche (eds.) El delito y el orden en perspectiva histórica, Rosario, Prohistoria, 2013, pp. 227-250.
} 


\section{Reflexiones finales}

Las autoridades provinciales esperaban que la construcción de las cárceles y la penitenciaría lograran que aquellos establecimientos pasaran de ser escuelas de enseñanza para el vicio y el crimen a verdaderas casas de corrección y mejora. El optimismo se mostraba en las palabras dichas para fundamentar una ley, realizar un balance de gestión y, claramente, en la inauguración de estos edificios que contaron con la presencia de las máximas autoridades de la República. Las dificultades en la organización y construcción de las edificaciones -fundamentalmente, pero no solo debido a cuestiones presupuestarias- no disminuyeron las esperanzas en las supuestas bondades del sistema penitenciario provincial.

Poco tiempo después de las inauguraciones en paralelo de las cárceles, las demandas comenzaron a fluir desde los 4 establecimientos para plantear diferentes problemáticas y necesidades. Las peticiones estaban centradas en la higiene ${ }^{70}$, la seguridad ${ }^{71}$ pero también en los aspectos vinculados a la administración y el presupuesto. Aun cuando no puedan sostenerse conclusiones definitivas dado que se trata de un estudio inicial es posible adelantar que el tipo de problemas reseñados se mantuvieron a lo largo del siglo. Estos formaban parte de un conjunto de dificultades de las diversas autoridades para consolidar su poder, y con él, al Estado que procuraban construir y consolidar. En tal sentido, los inconvenientes que fueron surgiendo en la edificación y funcionamiento de las cárceles reflejaron los del propio estado provincial bonaerense, considerado el más importante y poderoso entre los que conformaban entonces la República Argentina. Sin dudas, la precariedad material caracterizó buena parte del funcionamiento de estas instituciones de encierro. Cabe recordar que la necesidad de contar con un espacio específico para los penados llevó a establecerlo en Sierra Chica y que hacia 1885 la cárcel era un galpón rodeado de dos zanjas. ${ }^{2}$

\footnotetext{
7o AHPBA/MG, (1884) Inspección de Cárceles sobre el estado sanitario de la penitenciaría de Sierra Chica, 1/1884/13/1217/7/11/083, AHPBA/MG, (1885) Varios detenidos de la cárcel de Mercedes reclaman se mejoren las condiciones ambientales del establecimiento, 1/1885/15/1129/04/11/075.

${ }^{71}$ AHPBA/MG, (1884) Inspección de Guardia Cárceles. Sobre refuerzo de la guardia de Sierra Chica, 1/1884/5/497/o/2/11/083.

72 Aun cuando no podamos afirmarlo, es posible que la elección del espacio se vinculara con el aislamiento que podía ser tanto una ventaja -en relación a la seguridad- como un perjuicio pero también, y fundamentalmente, por las posibilidades de explotar el trabajo de los penados en las canteras existentes en la zona.
} 
Sin embargo, a la escasez presupuestaria se sumaba otro rasgo propio del entramado cada vez más complejo de autoridades que se fue organizando en la provincia a partir del crecimiento institucional que se dio durante el siglo XIX. Este no se conformó de manera vertical, donde una autoridad tenía una capacidad natural de ejercer un poder legítimo sobre otra subalterna. Quienes ejercían diferentes cargos parecían negociar en cada caso las facultades y prerrogativas con las autoridades centrales a partir de un conjunto diverso de variables. Esto que es claro en el caso de los jueces de paz pero también es perceptible en otras autoridades, como el caso del director de la Penitenciaría de Sierra Chica, Pedro Uriarte. De este modo, quizás sea posible entender a las instituciones de castigo establecidas en el espacio bonaerense conformando parte de ese pantano punitivo, caracterizado por Lila Caimari, que incluía además de las cárceles a todo un conjunto de prácticas nada novedosas y que seguían vigentes.73 $\mathrm{Y}$ que, paralelamente, formaba parte de un entramado de instituciones más amplio que constituyó al Estado provincial en un proceso que no tuvo nada de lineal.

\section{Bibliografía}

AGUIRRE, Carlos, Dénle duro que no siente. Poder y trasngresión en el Perú republicano, Perú, AFINED, 2011 [2008].

BLOCH, Marc, La sociedad feudal. Las clases y el gobierno de los hombres, Madrid, Akal, 1987 [1939].

BOHOSLAVSKY, Ernesto y CASULLO, Fernando, "Sobre los límites del castigo en la Argentina periférica. La cárcel de Neuquén (1904-1945)”, en Revista Quinto Sol, $\mathrm{N}^{\mathrm{o}}$ 7, La Pampa, 2003.

\footnotetext{
73 Hacemos referencia al destierro. AHPBA/Juzgado del Crimen (1877) Moreno, Pedro por homicidio a Juan Urquiza en el partido de Patagones, 40/1/340/34. En su declaración Moreno afirmó que su ocupación era la de "presidiario" ya que se encontraba en Patagones enviado por el juez del crimen de Mercedes a cumplir una pena de 10 años de destierro por otro homicidio.
} 
BUFFINGTON, Robert, Criminales y ciudadanos en el México moderno, México, Siglo XXI, 2001.

CAIMARI, Lila, "Castigar civilizadamente. Rasgos de la modernización punitiva en la Argentina (1827-1930)", en GAYOL, Sandra y KESSLER, Gabriel (comps.), Violencias, delitos y justicias en la Argentina, Buenos Aires, Editorial Manantial, 2002.

CANDIOTI, Magdalena, "Reformar útilmente la justicia': Jueces y leyes en la construcción del Estado en Buenos Aires en l década de 1820", en Marta IRUROZQUI y Mirian GALANTE (eds.), Sangre de Ley. Justicia y violencia en la institucionalización del Estado en América Latina, siglo XIX, Madrid, Ediciones Polifemo, 2011.

CANSANELLO, Carlos, "Justicias y penas en Buenos Aires. De los bandos de buen gobierno a la Constitución Nacional", en Sandra GAYOL y Gabriel KESSLER (comps.), Violencias, delitos y justicias en la Argentina, Buenos Aires, Editorial Manantial, 2002.

CORVA, María Angélica, Constituir el gobierno, afianzar la justicia. El Poder Judicial de la provincia de Buenos Aires (1853-1881), Rosario, Prohistoria, 2014.

FARGE, Arlette, La vida frágil. Violencia, poderes y solidaridades en el París del siglo XVIII, México, Instituto de Investigaciones Dr. José María Luis Mora, 1994.

FESSLER, Daniel, Derecho penal y castigo en Uruguay (1878-1907), Montevideo, Universidad de la República/CSIC, 2012.

FOUCAULT, Michel, Vigilar y castigar. El nacimiento de la prisión, Madrid, Siglo XXI, 1994 [1975].

FRADKIN, Raúl, “¿Misión imposible? La fugaz experiencia de los jueces letrados de Primera Instancia en la campaña de Buenos Aires (1822-1824)", en Darío Barriera (comp.), Justicias y fronteras. Estudios sobre historia de la justicia en el Río de la Plata. Siglos XVI-XIX, Murcia, Editum, 2009.

FRADKIN, Raúl y RATTO, Silvia, “¿Qué hacer con los prisioneros españoles? La construcción del 'enemigo' y las formas de dejar de serlo, Buenos Aires, 18171819”, en Darío BARRIERA (coord.), La justicia y las formas de la autoridad. Organización política y justicias locales en territorios de frontera. El Río de la Plata, Córdoba, Cuyo y Tucumán, siglos XVIII y XIX, Rosario, Red Columnaria, ISHIR/CONICET, 2010. 
GARCÍA BASALO, Alejo, “¿Un panóptico en Buenos Aires? La primera penitenciaria proyectada en Sudamérica”, en Épocas, No 8, 2013.

GARCÍA BASALO, Alejo, “¿Fue un panóptico la penitenciaría construida en Mendoza en 1865? Arquitectura y régimen en el primer reglamento penitenciario argentino", en XIV Jornadas Interescuelas/Departamentos de Historia, Mendoza, Universidad Nacional de Cuyo, 2013.

GAYOL, Sandra, "Sargentos, cabos y vigilantes: perfil de un plantel inestable en el Buenos Aires de la segunda mitad del siglo XIX”, en Boletín Americanista, $\mathrm{N}^{\circ}$ 46, 2006.

GONZALEZ ALVO, Luis, Modernizar el castigo. La construcción del régimen penitenciario de Tucumán (1880-1916), Rosario, Prohistoria, 2013.

GONZÁLEZ ALVO, Luis, "La normalización de la reforma penal latinoamericana. Un ensayo de análisis comparativo a través de los reglamentos de las penitenciarías de Santiago de Chile, Buenos Aires y Tucumán (1860-1900)”, en Luis CARO ZOTTOLA y Juliana PRESOTTO PEREIRA (orgs.) Poder judicial, políticas públicas y derechos humanos: análisis de sus relaciones desde una mirada interdisciplinaria en Argentina y Brasil, São Paulo, UNESP, 2014.

LEVAGGI, Abelardo, Las cárceles argentina de antaño (siglos XVIII y XIX), Buenos Aires, Ad Hoc, 2002.

LUCIANO, Melina, "La Penitenciaría de Córdoba: proceso de construcción, régimen interno y tensiones institucionales, 1887-1907", en Prohistoria, Año XVII, Nº 21, enero-junio 2014.

MOLLE, Alejandro, "Antecedentes documentales en torno al origen de la cárcel de Mercedes y primer quinquenio de labor (1854-1859)", inédito.

PALACIO, Juan Manuel, La paz del trigo. Cultura legal y sociedad local en el desarrollo agropecuario pampeano 1890-1945, Buenos Aires, Edhasa, 2004.

PIAZZI, Carolina, Justicia criminal y cárceles en Rosario (segunda mitad del siglo XIX), Rosario, Prohistoria, 2011.

RODRÍGUEZ MÉNDEZ, Lydia, Historia de la cárcel de Mercedes. Desde sus orígenes hasta 19oo, Buenos Aires, s/d/e, 1989.

SALVATORE, Ricardo, Subalternos, derechos y justicia penal. Ensayos de historia social y cultural argentina 1829-1940, Barcelona, Gedisa, 2010. SALVATORE, Ricardo y AGUIRRE, Carlos (eds.) The Birth of the Penitentiary in Latin 
America: Essays on Crimonology, Prison Reform and Social Control, 183o1940, Austin, University of Texas Press, 1996.

SALVATORE, Ricardo, AGUIRRE, Carlos y JOSEPH, Gilbert (eds.), Crime and Punishment in Latin America. Law and Society since Late Colonial Times, Durham \& Londres, Duke University Press, 2001.

SANTOS, Juan José, El Tata Dios. Milenarismo y xenofobia en las pampas, Buenos Aires, Sudamericana, 2008.

SERVICIO CORRECIONAL, Cárcel Departamental del Centro Mercedes, 1876-1976, Mercedes, 1976.

SERVICIO PENITENCIARIO BONAERENSE, Historia Institucional. Desde sus orígenes hasta la imposición del penitenciarismo, tomo I, La Plata, Ministerio de Justicia, 2006.

SILVA, Jeremías (2013) "El sistema penitenciario del Estado nacional entre 1930 y 1943”, en Ricardo SALVATORE y Osvaldo BARRENECHE (eds.) El delito y el orden en perspectiva histórica, Rosario, Prohistoria, 2013, pp. 227-250.

YANGILEVICH, Melina, Estado y criminalidad en la frontera sur de Buenos Aires (1850-1880), Rosario, Prohistoria, 2012.

YANGILEVICH, Melina, "Justicia de paz, territorio y construcción estatal en la frontera sur de Buenos Aires, primera mitad del siglo XIX", en XIV Jornadas Interescuelas/Departamentos de Historia, Universidad Nacional de Cuyo, Mendoza, 2013.

\section{Fuentes}

Archivo General de la Nación (Argentina), Sala X.

Archivo Histórico de la Provincia de Buenos Aires "Ricardo Levene", Sección Ministerio de Gobierno.

Registro Oficial de la Provincia de Buenos Aires (ROBA). 